\title{
Частичные соглашения \\ как форма сотрудничества государств \\ в рамках Совета Европы
}

Алисиевич E.C. *

Частичные соглашения - одна из наиболее динамично развивающихся и перспективных современных форм взаимодействия государств в рамках Совета Европы, которая активно используется государствами для гармонизации национального законодательства и правоприменительной практики, а также совместного решения таких актуальных проблем, как наркомания, коррупция, стихийные бедствия, и некоторых других. Частичные соглашения не являются международными договорами, представляя собой уникальную форму деятельности СЕ, во многом аналогичную деятельности в рамках программ организации. Партнерство на основании частичных соглашений СЕ отличается эффективностью и многоплановостью, низким уровнем бюрократизации и высоким уровнем гибкости. Российская Федерация участвует в работе шести из четырнадцати органов, созданных на основе частичных соглашений. Среди них Венецианская комиссия, Группа «ГРЕКО» и Группа «Помпиду».

Ключевые слова: Совет Европы; частичные соглашения; Венецианская комиссия; Группа «Помпиду»; Группа «ГРЕКО».

В состав Совета Европы входят 47 государств, которых, согласно ст. 1 Устава Совета Европы, объединяет общая цель: достижение «большего единства между членами организации во имя защиты и осуществления идеалов и принципов, являющихся их общим достоянием, и содействия их экономическому и социальному прогрессу». Для достижения поставленной цели государства - члены Совета Европы, в том числе Российская Федерация, активно взаимодействуют как с организаций, так и между собой на различных уровнях и в различных форматах, среди которых особое место занимает сотрудничество на основании участия в так называемых частичных соглашениях Совета Европы (partial agreements).

\footnotetext{
* Алисиевич Екатерина Сергеевна - к.ю.н., доцент кафедры международного права Российского университета дружбы народов. kataliss@yandex.ru.
} 
Взаимодействие государств в рамках частичных соглашений Совета Европы - одна из наиболее динамично развивающихся форм партнерства государств, которая в настоящее время активно используется и Российской Федерацией - участницей шести из четырнадцати действующих частичных соглашений ${ }^{1}$ - для совместного решения таких актуальных проблем, как наркомания, коррупция, стихийные бедствия, и некоторых других.

В соответствии с п. 48 Меморандума о взаимопонимании между Советом Европы и Европейским союзом 2007 г. партнерство на основании частичных соглашений играет важную роль в сотрудничестве Совета Европы и Европейского союза ${ }^{2}$. По состоянию на 1 октября 2008 г. Европейский союз участвует в работе четырех из четырнадцати органов, созданных на основании частичных соглашений Совета Европы.

Частичные соглашения как правовая основа для сотрудничества государств была предложена Комитетом министров Совета Европы (далее - КМ СЕ) в Резолюции «Частичные соглашения» ${ }^{3}$ (далее Резолюция 1951 г.), принятой этим органом на девятой сессии, проходившей 2 августа 1951 г.

Руководствуясь положениями ст. 20а Устава Совета Европы, КМ СЕ принял Резолюцию, дававшую право государствам - членам Совета Европы на добровольной основе с одобрения КМ СЕ объединяться в целях решения актуальных для них проблем путем разработки и присоединения к частичным соглашениям.

1 Российская Федерация присоединилась к следующим частичным соглашениям Совета Европы: к Соглашению о сотрудничестве в социальной сфере и области здравоохранения - 13 июля 2006 г., в статусе наблюдателя за деятельностью, связанной с реабилитацией и интеграцией инвалидов; к Соглашению об учреждении Группы государств по сотрудничеству в борьбе со злоупотреблением наркотиками и незаконной торговлей наркотиками - 8 мая 1999 г;; к Соглашению об учреждении Группы государств по борьбе с коррупцией - 1 февраля 2007 г.; к Соглашению об учреждении Европейской комиссии за демократию через право - 1 января 2002 г.; к Соглашению об учреждении Группы сотрудничества в целях предотвращения, защиты и организации помощи при естественных и технологических бедствиях - 19 апреля 1990 г. и к Соглашению об учреждении Европейской аудиовизуальной обсерватории - 15 декабря 1992 г.

${ }^{2}$ См.: Меморандум о взаимопонимании между Советом Европы и Европейским союзом CM(2007)74, принятый на 117-й сессии Комитета министров Совета Европы, состоявшейся 10 мая 2007 г. URL: http://www.wcd.coe.int/ (дата обращения: 01.10.2008).

3 См.: Резолюция Комитета министров Совета Европы (51)62 от 2 августа 1951 г. «Частичные соглашения» / URL: http://www.coe.int/t/cm/home_en.asp/ (дата обращения: 26.11.2008). 
«Частичный» характер соглашений был обусловлен тем, что его участниками могла быть «часть» государств - членов Совета Европы. При этом вступление в силу частичного соглашения не было обусловлено сдачей определенного числа ратификационных грамот. Заинтересованным государствам достаточно было представить КМ СЕ проект частичного соглашения и получить его одобрение в форме Резолюции, после принятия которой частичное соглашение вступало в силу, если иное не было предусмотрено в самом частичном соглашении.

Резолюция 1951 г. фактически носила рамочный характер, однако первые проекты частичных соглашений были одобрены КМ СЕ уже в 1956 и 1959 гг. Они касались сотрудничества в области финансов (учреждение Банка развития Совета Европы), а также взаимодействия в социальной сфере и сфере здравоохранения.

Эффективность партнерства на основании частичных соглашений Совета Европы предопределила активное развитие этой формы взаимодействия государств. В 80-е и 90-е гг. ХХ в. были приняты девять из четырнадцати частичных соглашений, действующих в настоящее время, а 14 мая 1993 г. на 92-й сессии КМ СЕ одобрил Резолюцию (93) 28 «О частичных и расширенных соглашениях» (далее - Резолюция 1993 г.), которая заменила Резолюцию 1951 г. ${ }^{4}$.

Из положений ч. 1 Резолюции 1993 г. следует, что опыт использования частичных соглашений Совета Европы как международно-правовой формы сотрудничества государств оказался успешен прежде всего потому, что частичные соглашения объединяли лишь заинтересованные государства.

При этом в Резолюции 1993 г. особо подчеркивается, что с проблемами, актуальными для государств - членов Совета Европы, такими как коррупция, наркотрафик и др., сталкиваются и государства, не входящие в состав Совета Европы. Большинство современных угроз демократической стабильности в обществе не имеют границ, поэтому борьба с ними не должна быть искусственно ограничена критерием членства в Совете Европы. Если для эффективной борьбы со стихийными бедствиями, помощи инвалидам или поддержки молодежи государствам членам Совета Европы необходимо сотрудничать с США, Канадой,

${ }^{4}$ См.: Резолюция Комитета министров Совета Европы (93)28 от 14 мая 1993 г. «Частичные и расширенные соглашения». URL: http://www.coe.int $/ \mathrm{t} / \mathrm{cm} / \mathrm{home}$ en.asp/ (дата обращения: 25.11.2008). 
с государствами Африки и Латинской Америки, то Совет Европы должен оказывать поддержку в решении проблем, общих для этих государств. Такая поддержка выражается в предоставлении возможности разрабатывать частичные соглашения и присоединяться к ним государствам, не входящим в состав Совета Европы, а также универсальным и региональным международным организациям.

Представляется, что привлекательность частичных соглашений Совета Европы как формы сотрудничества государств обусловлена не только факторами, упомянутыми в Резолюции 1993 г., но и некоторыми особенностями, присущими данной категории актов. Прежде всего, в отличие от конвенций, соглашений и хартий Совета Европы, частичные соглашения не являются международными договорами. Это, скорее форма деятельности Совета Европы, аналогичная деятельности в рамках программ организации, за некоторым исключением.

Во-первых, в частичных соглашениях предусматривается формирование собственного бюджета за счет взносов государств - участников конкретного соглашения. При этом некоторые частичные соглашения, например частичное соглашение, на основе которого учреждена Группа «Помпиду», предусматривают возможность финансирования отдельных проектов (мероприятий, программ) несколькими государствами - участниками частичного соглашения, в том числе с помощью взносов в созданный для этого фонд. Бюджет соглашения ежегодно утверждается членами КМ CE - участниками конкретного частичного соглашения. Финансирование программ, проектов, а также иные финансовые вопросы, возникающие в связи с действующими частичными соглашениями, решаются в порядке, определяемом государствами - участниками соответствующего соглашения.

Во-вторых, методы, формы и порядок работы в рамках частичного соглашения определяются исключительно участниками этого акта.

Безусловным достоинством частичных соглашений является практически ничем не ограниченная самостоятельность государств, избравших данную форму партнерства.

В соответствии с Резолюцией 1993 г. государства, инициирующие принятие нового частичного соглашения, должны представить КМ СЕ проект этого соглашения, а также проект устава органа, учреждаемого на его основании. КМ СЕ одобряет или отклоняет представленные проекты. В случае одобрения проекта частичного соглашения КМ СЕ принимает соответствующую Резолюцию. Например, 
15 декабря 1992 г. КМ СЕ принял Резолюцию R(92)70 «Расширенное частичное соглашение об учреждении Европейской аудиовизуальной обсерватории» ${ }^{5}$.

Несмотря на формально разрешительный характер, предусмотренный в Резолюции 1993 г., фактически КМ СЕ ни разу не отклонил представленный государствами проект частичного соглашения, поэтому на практике эта процедура носит скорее уведомительный характер.

В отличие от международных договоров Совета Европы, в частичных соглашениях содержится лишь самая общая информация о порядке взаимодействия соответствующих государств: предмет взаимодействия, возможные направления сотрудничества государств и орган - координатор деятельности участников, чья структура и компетенция, как правило, определяется в уставе соответствующего органа. Именно поэтому, очевидно, государства не ратифицируют частичные соглашения, а присоединяются к ним, лишь уведомляя о своем намерении Генерального секретаря Совета Европы.

Наконец, при разработке проекта частичного соглашения государства руководствуются принципом «меньше формализации - больше гибкости», следование которому позволяет быстро и эффективно адаптироваться к современным тенденциям, менять акценты в приоритетах деятельности, реорганизовывать созданные структуры и иным образом оперативно реагировать на меняющиеся условия жизнедеятельности общества.

Контроль над деятельностью структур, созданных на основании частичных соглашений, со стороны органов и институтов Совета Европы также минимален и сводится к рассмотрению и утверждению бюджета каждого частичного соглашения членами КМ СЕ - представителями государств - участников конкретного соглашения, а также к заслушиванию и утверждению ежегодных докладов органов, учрежденных в соответствии с конкретными частичными соглашениями. Все остальные вопросы решаются государствами без обязательного, но с возможным участием органов и институтов Совета Европы.

${ }^{5}$ См.: Резолюция Комитета министров Совета Европы R(92)70 от 15 декабря 1992 г. «Расширенное частичное соглашение об учреждении Европейской аудиовизуальной обсерватории», а также Резолюции Комитета министров R(97)4 от 20 марта 1997 г. и $\operatorname{Res}(2000) 7$ от 21 сентября 2000 г. URL: http://www.coe.int/t/cm/home_en.asp/ (дата обращения: 15.11.2008). 
Согласно Резолюции 1993 г., все частичные соглашения делятся на три группы: частичные соглашения, расширенные частичные соглашения и расширенные соглашения.

Частичные соглашения - это форма сотрудничества нескольких государств - членов Совета Европы. В настоящее время эта группа включает: соглашение о Банке развития Совета Европы6; соглашение по социальным вопросам и вопросам здравоохранения7; Конвенцию о разработке европейской фармакопеи ${ }^{8}$ : Европейскую карту для людейинвалидов 9 ; соглашение об учреждении Группы государств по сотрудничеству в борьбе со злоупотреблением наркотиками и незаконной торговлей наркотиками (Группы «Помпиду») ${ }^{10}$; соглашение об учреждении Группы сотрудничества государств в целях предотвращения, защиты и организации помощи при естественных и технологических бедствиях (EUR-OPA) ${ }^{11}$, а также соглашение об учреждении Европейского фонда поддержки совместного производства и распределения творческого синематографа и аудиовизуальных работ («Еуримагес» $)^{12}$.

${ }^{6}$ См.: Резолюция Комитета министров Совета Европы R(56)9 от 16 апреля 1956 г. «Частичное соглашение о Банке развития Совета Европы». URL: http://www.coe.int/t/ cm/home_en.asp/ (дата обращения: 25.11.2008).

7 См.: Резолюция Комитета министров Совета Европы R(59)23 от 16 ноября 1959 г. «Частичное соглашение по социальным вопросам и вопросам в области здравоохранения», а также Резолюции Комитета министров Совета Европы R(61)40 от 16 декабря 1961 г.; R(96)34 от 2 октября 1996 г.; R(96)35 от 2 января 1996 г. URL: http://www.coe. int $/ \mathrm{t} / \mathrm{cm} / \mathrm{home}$ en.asp/ (дата обращения: 25.11.2008).

${ }^{8}$ См.: Конвенция о разработке европейской фармакопеи // Серии европейских договоров CДСЕ №50. URL: http://conventions.coe.in/ (дата обращения: 18.11.2008).

${ }^{9}$ См.: Европейская карта для людей-инвалидов. Карта пока не принята.

10 См.: Резолюция Комитета министров Совета Европы R(80)2 от 27 марта 1980 г. «Частичное соглашение об учреждении Группы государств по сотрудничеству в борьбе со злоупотреблением наркотиками и незаконной торговлей наркотиками», а также Резолюция Комитета министров Совета Европы R(80)15 от 17 сентября 1980 г. URL: http://www.coe.int/t/cm/home_en.asp/ (дата обращения: 10.11.2008).

${ }^{11}$ См.: Резолюция Комитета министров Совета Европы R(87)2 от 20 марта 1987 г. «Частичное соглашение об учреждении Группы сотрудничества в целях предотвращения, защиты и организации помощи при естественных и технологических бедствиях». URL: http://www.coe.int/t/cm/home_en.asp/ (дата обращения: 25.11.2008).

${ }^{12}$ См.: Резолюция Комитета министров Совета Европы R(88)15 от 26 октября 1988 г. «Частичное соглашение об учреждении Европейского Фонда поддержки совместного производства и распределения творческого синематографа и аудиовизуальных работ» (с изменениями и дополнениями, внесёнными следующими Резолюциями Комитета министров Совета Европы: R(89)6 от 15 июня 1989 г.; R(90)34 от 30 ноября 1990 г.; 
Участниками расширенных частичных соглашений могут быть государства - члены Совета Европы, государства, не входящие в состав этой организации, а также универсальные и региональные международные организации. Данная группа включает шесть соглашений: соглашение об учреждении Европейского центра глобальной зависимости и солидарности (Центра «Север - Юг») ${ }^{13}$; соглашение по Карте молодежи с целью продвижения и облегчения продвижения молодежи в Европе ${ }^{14}$; соглашение об учреждении Европейской аудиовизуальной обсерватории ${ }^{15}$; соглашение об учреждении Европейского центра современных языков ${ }^{16}$; соглашение об учреждении Группы государств по борьбе с коррупцией (Группы «ГРЕКО») ${ }^{17}$ и соглашение по спорту (EPAS) ${ }^{18}$.

Расширенные соглашения - это соглашения, участниками которых являются все 47 государств - членов Совета Европы, к которым могут присоединиться государства, не входящие в состав Совета Европы,

$\mathrm{R}(92) 3$ от 10 февраля 1992 г.; $\mathrm{R}(93) 10$ от 3 апреля 1993 г. и $\mathrm{R}(98) 10$ от 2 июля 1998 г.). URL: http://www.coe.int/t/cm/home_en.asp/ (дата обращения: 28.11.2008).

${ }^{13}$ См.: Резолюция Комитета министров Совета Европы R(89)14 от 16 ноября 1989 г. «Расширенное частичное соглашение об учреждении Европейского Центра глобальной зависимости и солидарности», а также Резолюция Комитета министров R(93)51 от 21 октября 1993 г. URL: http://www.coe.int/t/cm/home_en.asp

14 См.: Резолюция Комитета министров Совета Европы ResAP(2003)1 от 15 января 2003 г. «Расширенное частичное соглашение по Карте молодежи с целью продвижения и облегчения продвижения молодежи в Европе», а также Резолюция Комитета министров Совета Европы R(91)20 от 13 сентября 1991 г. URL: http://www.coe.int/t/ cm/home_en.asp (дата обращения: 14.11.2008).

${ }^{15}$ См.: Резолюция Комитета министров Совета Европы R(92)70 от 15 декабря 1992 г. «Расширенное частичное соглашение об учреждении Европейской аудиовизуальной обсерватории», а также Резолюции Комитета министров R(97)4 от 20 марта 1997 г.и Res(2000)7 от 21 сентября 2000 г. URL: http://www.coe.int/t/cm/home_en.asp/ (дата обращения: 25.11.2008).

16 См.: Резолюция Комитета министров Совета Европы R(94)10 от 8 апреля 1994 г. «Расширенное частичное соглашение об учреждении Европейского центра современных языков», а также Резолюция Комитета министров R(98)11 от 2 июля 1998 г. URL: http://www.coe.int/t/cm/home_en.asp/ (дата обращения: 25.11.2008).

${ }_{17}$ См.: Резолюция Комитета министров Совета Европы R(98)7 от 5 мая 1998 г. «Расширенное частичное соглашение об учреждении Группы государств по борьбе с коррупцией», а также Резолюция Комитета министров R(99)5 от 1 мая 1999 г. URL: http:// www.coe.int/t/cm/home_en.asp/ (дата обращения: 25.11.2008).

18 См.: Резолюция Комитета министров Совета Европы Res(2007)8 от 11 мая 2007 г. «Расширенное частичное соглашение по спорту». URL: http://www.coe.int $/ \mathrm{t} / \mathrm{cm} /$ home_en.asp/ (дата обращения: 25.11.2008). 
а также универсальные и региональные международные организации. Эта группа представлена единственным соглашением об учреждении Европейской комиссии за демократию через право (Венецианской комиссии) ${ }^{19}$.

Для присоединения к любому действующему частичному соглашению государству - члену Совета Европы достаточно уведомить о своем намерении Генерального секретаря Совета Европы.

Государство, не входящее в состав Совета Европы, а также международная универсальная (региональная) организация, желающая стать участником какого-либо частичного соглашения, должны обратиться с соответствующей просьбой к КМ СЕ, который после консультаций с этим государством может пригласить его присоединиться к расширенному частичному соглашению или расширенному соглашению.

Государство, не являющееся членом Совета Европы, а также международная универсальная или региональная организация вправе обратиться к КМ СЕ с просьбой предоставить ему (ей) статус наблюдателя при органе, учреждаемом участниками конкретного частичного соглашения для координации деятельности государств в соответствующей области. После проведения необходимых консультаций КМ СЕ может пригласить заинтересованное государство или международную универсальную (региональную) организацию присоединиться к расширенному частичному или расширенному соглашению в качестве наблюдателя.

По состоянию на 1 октября 2008 г. в рамках Совета Европы действуют четырнадцать частичных соглашений, на основании каждого из которых учрежден орган, оказывающий государствам-участникам содействие в решении конкретной проблемы.

Органы, созданные на основании частичных соглашений Совета Европы, различаются по предмету и объекту регулирования, по своим целям и задачам, структуре и порядку работы. Они не создаются по единому образцу и кардинально отличаются друг от друга по принципам организации деятельности. Например, Европейская аудиовизуальная обсерватория была создана в 1992 г. в Страсбурге на основании расширенного частичного соглашения Совета Европы. В работе

${ }^{19}$ См.: Резолюция Комитета министров Совета Европы Res(2002)3 от 21 февраля 2002 г. «Расширенное соглашение об учреждении Европейской комиссии за демократию через право», а также Резолюция Комитета министров R(90)6 от 10 мая 1990 г. URL: http:// www.coe.int $/ \mathrm{t} / \mathrm{cm} / \mathrm{home}$ en.asp/ (дата обращения: 25.11.2008). 
обсерватории принимают участие государства - члены Совета Европы, в том числе Российская Федерация ${ }^{20}$, а также Европейское сообщество. Основное направление деятельности Обсерватории - систематический сбор, документальное оформление, подготовка и распространение тематической информации о состоянии аудиовизуального сектора в Европе. Обсерватория специализируется на работе, связанной со сбором информации о рынках и нормативном регулировании, а также кинои телепроизводстве и его финансировании. Обсерватория ведет базы данных по экономическим и юридическим вопросам и предоставляет через Интернет доступ на свой информационный портал, посвященный проблемам аудиовизуального сектора ${ }^{21}$.

Частичное соглашение по предупреждению, защите и организации помощи в случае крупных природных бедствий и технологических катастроф (EUR-OPA) было заключено в марте 1987 г.22 В работе органа, учрежденного на основании этого соглашения, принимают участие не только государства - члены Совета Европы ${ }^{23}$, которых в настоящее время 24, в том числе Российская Федерация, но и некоторые международные организации. Среди них Европейская комиссия, ЮНЕСКО, BO3, гуманитарное отделение ООН и Красный Крест. Статус наблюдателя предоставлен Алжиру, Ливану, Марокко и Японии. Основными целями сотрудничества государств в области борьбы со стихийными бедствиями и технологическими катастрофами являются: укрепление сотрудничества участников соглашения в целях обобщения их опыта и ресурсов для эффективного использования в чрезвычайной ситуации,

20 См.: Распоряжение Правительства РФ от 3 июня 2002 г. № 747-р «Об обеспечении участия России в деятельности общеевропейской межправительственной организации «Европейская аудиовизуальная обсерватория». URL: http://www.government.ru/ government

${ }^{21}$ См.: Официальный сайт Европейской аудиовизуальной обсерватории. URL: http:// www.obs.coe.int

${ }^{22}$ См.: Резолюция Комитета министров Совета Европы R(87)2 от 20 марта 1987 г. «Частичное соглашение об учреждении Группы сотрудничества в целях предотвращения, защиты и организации помощи при естественных и технологических бедствиях». URL: http://www.coe.int/t/cm/home_en.asp/ (дата обращения: 25.11.2008).

23 Государства - участники частичного соглашения, учреждающего Центр по предупреждению, защите и организации помощи в случае крупных природных бедствий и технологических катастроф: Албания, Армения, Азербайджан, Бельгия, Болгария, Греция, Грузия, Кипр, Люксембург, Испания, бывшая республика Югославии Македония, Мальта, Молдова, Монако, Португалия, Румыния, Россия, Сан-Марино, Турция, Украина, Франция и Хорватия. 
а также поддержка создания европейских специализированных центров (в настоящее время их более 20), которые способствуют вовлечению государств в решение общей для них проблемы предотвращения и борьбы со стихийными бедствиями и технологическими катастрофами.

Несмотря на отличительные особенности, присущие каждому органу, действующему на основании частичных соглашений, эти органы можно разделить на три группы.

Прежде всего это органы, деятельность которых направлена на гармонизацию законодательства и правоприменительной практики государств. К их числу относится, например, Венецианская комиссия (далее - Комиссия), которая была учреждена в 1990 . на основании частичного соглашения Совета Европы как форум для обсуждения актуальных проблем права, а также орган, оказывающий государствам содействие в выработке нормативно-правовых актов, прежде всего по вопросам конституционного права ${ }^{24}$. В настоящее время членами этого соглашения является 51 государство ${ }^{25}$, в том числе Российская Федерация ${ }^{26}$. В качестве ассоциированного члена в работе Комиссии принимает участие Беларусь. Статус наблюдателя при Комиссии имеют Аргентина, Израиль, Казахстан, Канада, Мексика, США, Уругвай и Япония. Европейская комиссия обладает специальным статусом, а Южная Африка - специальным статусом партнера по сотрудничеству.

${ }^{24}$ См.: Резолюция Комитета министров Совета Европы (90)6 от 10 мая 1990 г. «О частичном соглашении, учреждающем Европейскую комиссию за демократию через право». URL: http://www.venice.coe.int, а также Резолюцию Комитета министров Совета Европы (2002)3 от 21 февраля 2002 г. «О принятии пересмотренного Устава Европейской комиссии за демократию через право». URL: http://www.venice.coe.int/ (дата обращения: 25.11.2008).

${ }^{25}$ Государства - члены расширенного соглашения: Австрия, Азербайджан, Албания, Андорра, Армения, Бельгия, Болгария, бывшая югославская республика Македония, Великобритания, Венгрия, Германия, Греция, Грузия, Дания, Ирландия, Исландия, Испания, Италия, Кипр, Кыргызстан, Латвия, Литва, Лихтенштейн, Люксембург, Мальта, Молдова, Марокко, Нидерланды, Норвегия, Польша, Португалия, Республика Корея, Российская Федерация, Румыния, Сан-Марино, Словакия, Словения, Турция, Украина, Франция, Финляндия, Хорватия, Черногория, Чешская Республика, Чили, Швейцария, Швеция и Эстония.

${ }^{26}$ См.: Постановление Правительства РФ № 748 «О присоединении Российской Федерации к частичному соглашению 1990 года, учреждающему Европейскую комиссию за демократию через право от 27 октября 2001 г. URL: http://www.government.ru/ government/ (дата обращения: 25.11.2008). 
Цели Комиссии, сформулированные в ст. 1 Устава ${ }^{27}$, сводятся к следующим: детальное изучение правовых систем государств - участников соглашения, прежде всего для сближения этих систем; претворение в жизнь принципов правового государства и демократии; исследование проблем, связанных с функционированием, укреплением и развитием демократических институтов. При этом к числу приоритетных направлений деятельности Комиссии относятся вопросы, которые касаются действующего конституционного и административного законодательства государств - участников соглашения, механизмов, обеспечивающих эффективное функционирование демократических институтов и их укрепление, реализации принципа верховенства закона, а также основны прав и свобод человека, прежде всего, права граждан участвовать в работе общественных институтов, наконец, вклада органов местного и регионального самоуправления в развитие демократии.

Комиссия работает по нескольким основным направлениям: содействие государствам в области конституционного права ${ }^{28}$; сотрудничество с конституционными судами ${ }^{29}$; содействие государствам в проведении выборов и референдумов, «транснациональные» исследования, доклады и семинары, а также организация семинаров, курсов повышения квалификации и консультаций.

Деятельность Комиссии является наиболее масштабной и всеобъемлющей по сравнению с деятельностью органов, созданных на основании других частичных соглашений. Это обусловлено как длительным периодом деятельности Комиссии, так и числом ее участников, следовательно, финансовыми, информационными, техническими и другими ресурсами. В настоящее время деятельность Комиссии направлена на разработку Европейской конвенции о стандартах в области избирательного права и процесса как итога длительного периода работы Комиссии, в которой были бы объединены правовые стандарты Совета Европы в области избирательного права и процесса.

Вторая группа органов включает структуры, призванные вырабатывать единые подходы к решению конкретных проблем, которые

27 Здесь и далее речь идёт о пересмотренном Уставе.

${ }^{28}$ См. подробнее: Constitutional courts and European integration//Science and technique of democracy. №3 6, 2005.

${ }^{29}$ См. подробнее: European integration and constitutional law//Science and technique of democracy №3, 2002, а также The role of the Constitutional Court in the consolidation of rule of law (Proceedings, Bucharest, 8-10 June 1994)//Science and Technique of Democracy № 10, 1998. 
государства не могут решить самостоятельно. К их числу относится Группа «Помпиду», которая была создана в 1971 г. государствами, которых объединяла общая цель: борьба с наркотрафиком и наркозависимостью. В настоящее время в работе Группы участвует 35 государств ${ }^{30}$, в том числе Российская Федерация ${ }^{31}$, присоединившаяся к соглашению в 1999 г. Участником Группы является также Европейская комиссия. С Группой сотрудничают Албания, Латвия и Украина. В некоторых программах и по принципу ad hoc в работе Группы участвуют США и Канада.

Миссия Группы определена следующим образом: содействие развитию в государствах-участниках современной, многоплановой, эффективной и обоснованной политики, которая позволила бы объединить три составляющих: политику, практику и науку для выработки и применения на местах программ по борьбе с наркотиками ${ }^{32}$. Для достижения поставленной цели Группа использует два принципа: принцип гибкости подходов и способность быстро адаптировать свою работу к современным условиям.

Группа также играет роль форума, в рамках которого министры, должностные лица, эксперты и специалисты взаимодействуют, а также обмениваются информацией и практическим опытом в области борьбы с незаконным употреблением и оборотом наркотических средств. Применяя в своей работе многопрофильный подход, эта организация уже более 30 лет является своеобразным мостом между учеными, практиками и политиками, между специалистами, занимающимися проблемами наркомании, и гражданским обществом, между государствами членами Совета Европы и остальными государствами.

Третья группа органов состоит из контрольных органов или органов - координаторов взаимодействия государств в связи или на основе

30 См.: государства - участники Группы «Помпиду»: Австрия, Азербайджан, Бельгия, Болгария, Венгрия, Германия, Греция, Дания, Ирландия, Испания, Исландия, Италия, Кипр, Лихтенштейн, Литва, Люксембург, Мальта, Нидерланды, Норвегия, Польша, Португалия, Румыния, Российская Федерация, Сан-Марино, Словакия, Словения, Великобритания, Турция, Финляндия, Франция, Хорватия, Чехия, Швеция, Швейцария, Эстония.

31 См.: Постановление Правительства Российской Федерации от 8 мая 1999 г. № 506 «О присоединении Российской Федерации к Группе по сотрудничеству в борьбе со злоупотреблением наркотиками и их незаконным оборотом («Группе Помпиду»). URL: http:/www.government.ru/government/ (дата обращения: 25.11.2008).

${ }^{32}$ См.: Connecting research, policy and practice - Lessons learned, challenges ahead - Proceedings, Strategic conference, Strasbourg, 6-7 April 2004. URL: http://www.pompidou. coe.int/ (дата обращения: 04.10.2008). 
уже действующей конвенции (соглашения) Совета Европы. К числу таких органов относится Группа «ГРЕКО», учрежденная в целях контроля над соблюдением государствами Конвенции об уголовной ответственности за коррупцию 1998 г. ${ }^{33}$ и Конвенции о гражданско-правовой ответственности за коррупцию 1999 г. ${ }^{34}$.

Совет Европы рассматривает коррупцию как угрозу верховенству права, стабильности демократических институтов, правам и свободам человека, социальному и экономическому прогрессу и поэтому, справедливо полагая, что с коррупцией сталкиваются практически все государства - члены Совета Европы, относит это явление к числу транснациональных проблем. Решение данной проблемы осложнено тем, что коррупция может одновременно рассматриваться с точки зрения уголовного, гражданского и административного права ${ }^{35}$. В связи с этим цель Группы «ГРЕКО» обусловлена двумя взаимосвязанными направлениями деятельности Совета Европы в области борьбы с коррупцией, организованной преступностью и отмыванием денег: развитие и совершенствование европейских правовых стандартов в соответствующей области на основе Конвенции об уголовной ответственности за коррупцию 1998 г., Конвенции о гражданской ответственности за коррупцию 1999 г., Конвенции об отмывании, выявлении, изъятии и конфискации доходов от преступной деятельности 1990 г. ${ }^{36}$, а также ряде резолюций и рекомендаций органов Совета Европы и мониторинг соблюдения выработанных стандартов.

Российская Федерация принимает активное участие в деятельности как перечисленных выше органов, так и иных структур, учрежденных на основании частичных соглашений Совета Европы. При этом интенсивность деятельности России в этом направлении стремительно растет.

Так, Центральная избирательная комиссии России совместно с государствами - партнерами по СНГ подготовила проект Европейской конвенции о стандартах выборов, избирательных прав и свобод, который

${ }^{33}$ См.: Конвенция Совета Европы «Об уголовной ответственности за коррупцию» от 4 ноября 1998 г. URL: http://conventions.coe.int

${ }^{34}$ См.: Конвенция Совета Европы «О гражданской ответственности за коррупцию» от 4 ноября 1999 г. URL: http://conventions.coe.int

35 См.: Della P., Donatella C., Mény I. Democracy and Corruption in Europe. London. 1997. P. 36.

${ }^{36}$ См.: Конвенции Совета Европы об отмывании, выявлении, изьятии и конфискации доходов от преступной деятельности от 8 ноября 1990 г. URL: http://conventions.coe.int 
был единогласно одобрен 26-28 сентября 2002 г. в Москве на очередной конференции Ассоциации организаторов выборов стран Центральной и Восточной Европы (далее - АОВЦВЕ). 27 ноября 2002 г. проект Конвенции был официально передан Парламентской Ассамблее Совета Европы (ПАСЕ). 30 января 2003 г. сессия ПАСЕ одобрила Резолюцию 1320(2003), в которой отметила, что Совет Европы, опираясь на свою особую роль «хранителя» демократии в Европе, должен взять на себя инициативу по кодификации правил проведения выборов. В связи с этим ПАСЕ рекомендовала КМ СЕ предпринять шаги по выработке общеевропейского документа о стандартах выборов, который опирался бы, в частности, и на проект Конвенции, подготовленный в рамках $\mathrm{AOBЦBE}^{37}$. В марте 2004 г. проект был поддержан Европейской комиссией «За демократию через право» ${ }^{38}$.

Начиная с 1999 г. Россия сотрудничает с Группой «Помпиду». На сегодняшний день в России реализуется более 300 программ, проектов и мероприятий в рамках деятельности Совета Европы, направленных прежде всего на профилактику и снижение потребления наркотиков, на пресечение наркоторговли, трафика сырья, наркотических препаратов и психотропных веществ.

На территории Российской Федерации реализуются три пилотных проекта, смысл которых заключается в том, чтобы на трех разных территориях отработать три разных метода профилактики.

В Екатеринбурге была запущена программа «Сеть поддержки по профилактике наркомании для родителей и специалистов», реализованная на территории Уральского федерального округа в 2004-2006 гг. Главной целью проекта стало создание основы для Виртуального ресурсного тренинг-центра, который стал платформой для контактной сети проведения обучения, предоставления консультационных услуг и услуг по взаимопомощи для родителей и специалистов.

В Челябинской области, где высока активность организаций некоммерческого сектора, было решено развивать группы взаимопомощи - направление достаточно новое и не так широко распространенное в России. Этот проект носит название «Группы взаимопомощи».

${ }^{37}$ См.: Официальный сайт Центральной избирательной комиссии Российской Федерации: http://www.cikrf.ru

${ }^{38}$ Станских С.Н. Кристоф Грабенвартер о проекте Конвенции Совета Европы «О стандартах выборов, избирательных прав и свобод» (продолжение) // Государственная власть и местное самоуправление. М.: Юрист. 2004. № 4. С. 35-38. 
В Курганской области проводится серия тренингов для специалистов и волонтеров, занимающихся профилактикой наркомании; проект здесь так и называется - «Тренинги для специалистов и волонтеров».

Коррупция, как явление социальное, в той или иной степени затрагивает интересы практически всех государств. В России этот феномен приобретает все более и более угрожающие масштабы. Видимо, поэтому 27 января 1999 г. Россия подписала Конвенцию об уголовной ответственности за коррупцию 1998 г, а в 2006 г. ратифицировала этот акт ${ }^{39}$.

Поскольку ратификация Конвенции об уголовной ответственности за коррупцию ведет к автоматическому включению государства в число участников Группы «ГРЕКО», Россия также вошла в ее состав с 1 февраля 2007 г. 19 марта 2007 г. российская делегация впервые приняла участие в пленарном заседании Группы « ГРЕКО».

Таким образом, частичные соглашения Совета Европы - это особая правовая форма сотрудничества государств в рамках Совета Европы, которая служит правовой основой для взаимодействия государств по конкретным актуальным для них вопросам, а также для учреждения органа, который оказывает содействие государствам - участникам соглашения в достижении поставленной цели и, занимаясь сбором и обобщением опыта заинтересованных государств, содействует гармонизации законодательства и правоприменительной практики участвующих субъектов. Партнерство на основании частичных соглашений отличается эффективностью и многоплановостью, низким уровнем бюрократизации и высоким уровнем гибкости. Совокупность перечисленных факторов позволяет рассматривать сотрудничество на основании частичных соглашений как одну из наиболее перспективных форм взаимодействия государств в рамках Совета Европы.

\section{Библиографический список}

Станских С.Н. Кристоф Грабенвартер о проекте Конвенции Совета Европы «О стандартах выборов, избирательных прав и свобод». (Продолжение) // Государственная власть и местное самоуправление. М.: Юрист. 2004. № 4. C. 35-38.

${ }^{39}$ См.: Федеральный закон «О ратификации Конвенции об уголовной ответственности за коррупцию» № 125-Ф3 от 25 июля 2006 г. // Российская газета 28 июля 2006 г. № 4130 . 
Constitutional courts and European integration//Science and technique of democracy. № 36, 2005.

Connecting research, policy and practice - Lessons learned, challenges ahead Proceedings, Strategic conference, Strasbourg, 6-7 April 2004. URL: http://www. pompidou.coe.int/ (дата обращения: 04.10.2008).

Della P., Donatella C., Mény I. Democracy and Corruption in Europe. London. 1997.

European integration and constitutional law//Science and technique of democracy № 3, 2002.

The role of the Constitutional Court in the consolidation of rule of law (Proceedings, Bucharest, 8-10 June 1994) // Science and Technique of Democracy № 10, 1998.

\section{Partial Agreements as Form of Cooperation of the States in the Framework of the Council of Europe}

(Summary)

Ekaterina S. Alisievich*

Partial agreements is one of the most dynamically developing and promising modern forms of cooperation of the states in the framework of the Council of Europe, that is actively used by the states for harmonization of national legislation and law-enforcement practice, as well as for joint solution of such urgent problems as struggle with drug abuse, corrupt practices, natural disasters and some others. Partial agreements are not international treaties; they represent a unique form of activities of the Council of Europe. In many ways, these activities are similar to those carried out in the framework of the programs of the organization. Partnership based on partial agreements of the Council of Europe is effective and multidimensional; it has low level of bureaucratization and high level of flexibility. Russian Federation participates in work of six out of fourteen bodies created based on partial agreements. Among them are such as the Venice Commission, the GRECO group, and the Pompidou group.

Key words: Council of Europe; partial agreements; Venice Commission; Pompidou Group; GRECO Group.

* Ekaterina S. Alisievich - Ph.D. in law, associate professor of the Chair of International law, Peoples’ Friendship University of Russia. kataliss@yandex.ru. 